\title{
Pattern of Valvular Involvement and Demographic Features of Patients on Injection Benzathine Penicillin at Dhulikhel Hospital
}

Humagain $\mathrm{S}^{1}$, Gurung $\mathrm{R}^{1}$, Pant $\mathrm{P}^{1}$, Koju $\mathrm{R}^{1}$, Bedi TRS ${ }^{1}$

${ }^{1}$ Department of Internal Medicine, Dhulikhel Hospital, Kathmandu University Hospital

\section{Abstract \\ Background}

Rheumatic heart disease (RHD) is the most common cardiovascular disease in children and young adults. Though declined and almost non-existent in developed nations, RHD is still one of the leading cause for premature death and disability in developing countries. Prevalence of RHD is high in both rural as well as urban area of Nepal. Present study is designed to look at the pattern of valvular involvement and demographic features in RHD.

\section{Methods}

326 Patients indicated for inj. Benzathine penicillin were selected and echocardiograph performed to see the pattern of vavular involvement. Data analysis was done using SPSS 17.

\section{Result}

The most common type of lesion was mixed type with mitral valve involvement. MR was the most common isolated lesion. MS was more commonly seen in females whereas AS was more common in males. Secondary prophylaxis was more common than primary prophylaxis.

\section{Conclusion}

RHD still being a major problem and a preventable disease so extensive screening program is required to identify them early and prevent the complication.

Keywords Acute rheumatic fever, RHD, MS, MR, AS, AR, Inj Benzathine Penicillin 


\section{Introduction}

Rheumatic heart disease (RHD) is the most common cardiovascular disease in children and young adults. ${ }^{1}$ It is estimated to exist with prevalence of 15.6 million cases with 282000 new cases and 233000 deaths each year. ${ }^{2}$ Though declined and almost nonexistent in developed nations, still one of the leading cause for premature death and disability in developing countries. ${ }^{3,4}$ Prevalence of RHD is high in both rural as well as urban area of Nepal. ${ }^{5}$

It is important to diagnose the pattern and severity of valvular involvement in RHD, so that patients can undergo invasive treatment like PTMC, valve repair or valve replacement at appropriate time. Patients not requiring the invasive treatment can be kept on regular follow up with prophylaxis and possible consequences of disease can be discussed earlier.

Present study is designed to look at the pattern of valvular involvement and demographic features in RHD. This information can be useful for the clinicians as well as the health policy makers.

\section{Methods}

All the patients who were indicated for injection Benzathine penicillin at Dhulikhel hospital were included in the study. Study period was from April $1^{\text {st }} 2012$ to $31^{\text {st }}$ July 2012. There were total 326 patients. 4 months duration was taken so that minimum number patients were missed from the study. In all of the patients demographic features like age, sex, duration of injection, intervention, no of hospital admission was noted down. All the patients underwent echocardiographic study using TOSHIBA Power Vision 6000, performed by either one of the two cardiologists present. Standard guidelines including 2D, M mode, Doppler were followed to identify different valvular lesion. .,7 $^{6}$

Statiscal analysis is done using SPSS 17. Where ever applicable students t-test and chi-square test were applied.

\section{Results}

Age range was from 6 years to 48 years, with mean age being $22+/-6.4$ years. Out of 326 patients 178 (54.6\%) were female and $148(45.4 \%)$ were male with $p$ value of 0.01 which was a statistically significant. Average duration of injection Benzathine penicillin was 46+/- 6 months. Total of $31(9.51 \%)$ patients had undergone intervention. 22 had PTMC (percutaneous transluminal mitral commissurotomy) and 9 had valve replacement.

During the study period a total of 32 new cases were indicated for Inj. Benzathine Penicillin. Out of which RHD cases were 28 and ARF (acute rheumatic fever) only 4.In the RHD group $20(71.43 \%)$ were female and $8(28.57 \%)$ were male. And 8 of the females diagnosed were in their $3^{\text {rd }}$ triemester of pregnancy. Out of 4 ARF cases 2 were male and 2 were female.

During the study period 2 patients had to be treated for infective endocarditis. Three patients were sent for immediate PTMC and two for valve replacement. Table 2 shows that the most common form of isolated lesion involved was MR. 63 (19.33\%), followed by MS 38(11.66\%), AR $9(2.76 \%)$ and AS 5(1.53\%). However the table also clearly shows that mixed type of lesion is much more common with involvement of mitral valve.

Table 3 shows that isolated MS was more common among females 22 vs males 14 with $p$ value of 0.01 and AS was more common among males 4 vs females 1 with $p$ value of 0.02 . There was no statistical difference among male and female in other pattern of valvular involvement.

Fig.1. Distribution of patients according to sex

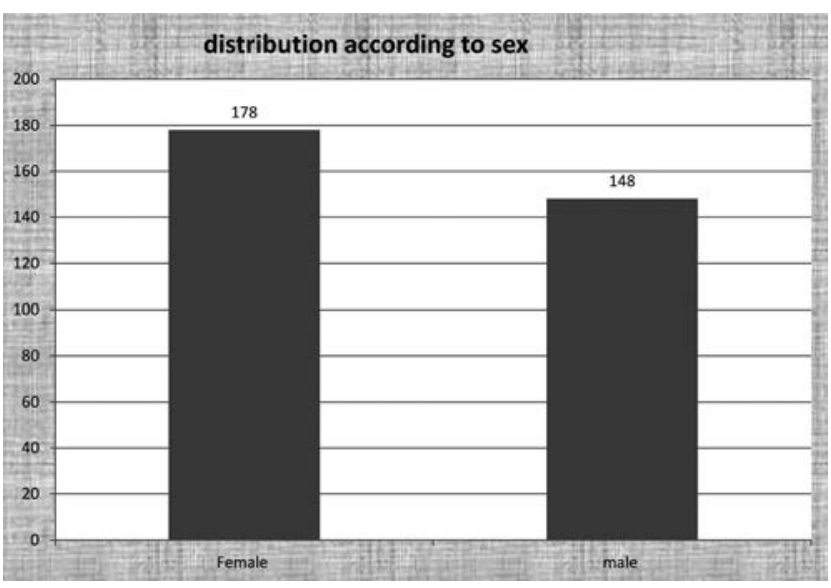

Fig.2.Distibution of Patients according to the intervention procedure

Intervention Procedure

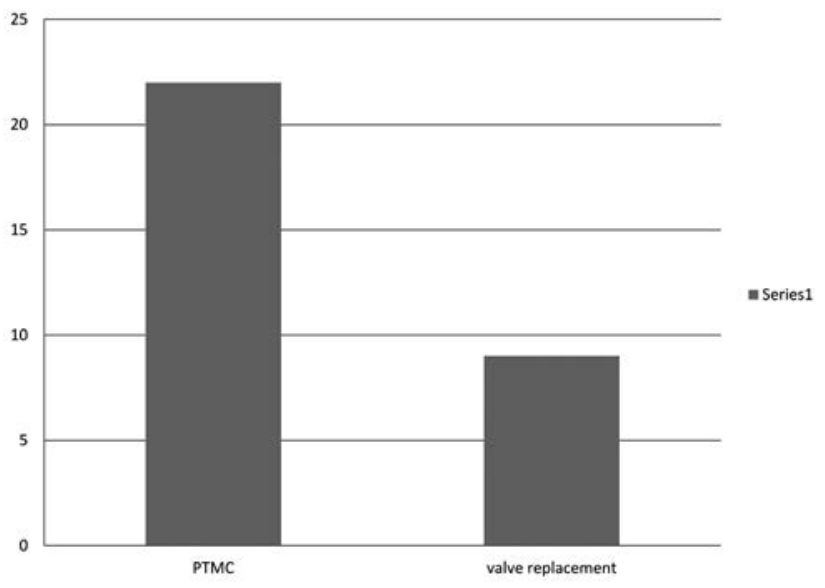


Fig.3. Distribution of patients according to the number of hospital admissions

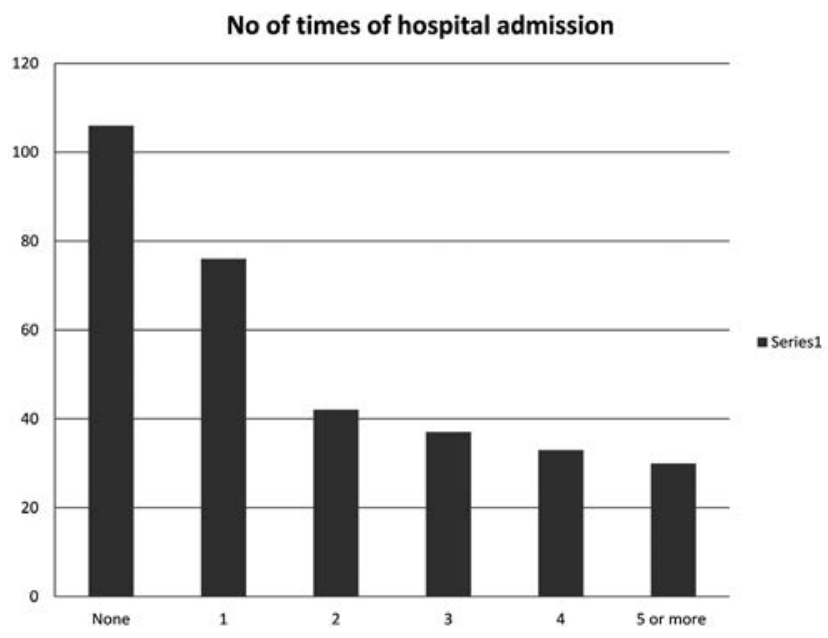

Table.1. Distribution of newly diagnosed cases

\begin{tabular}{|c|c|c|}
\hline & Total number & Percentage \% \\
\hline Rheumatic heart disease & 28 & 87.50 \\
\hline Male & 8 & 28.57 \\
\hline Female & 20 & 71.43 \\
\hline $3^{\text {rd }}$ Triemester of pregnancy Acute & 8 & 28.57 \\
\hline rheumatic fever & 4 & 12.5 \\
\hline Male & 2 & 6.25 \\
\hline Female & 2 & 6.25 \\
\hline
\end{tabular}

Table.2. Distribution of patients according to the valvular involvement

\begin{tabular}{lccc|}
\multicolumn{4}{c}{ Pattern of valvular involvement in echocardiographic finding } \\
\hline & Pure (\%) & Mixed (\%) & Total (\%) \\
No Valvular involvement & & & $36(11.04)$ \\
Valvular involvement & & & $290(88.95)$ \\
MS & $38(11.66)$ & $132(41.72)$ & $170(52.14)$ \\
MR & $63(19.33)$ & $163(50.00)$ & $226(69.33)$ \\
AS & $5(1.53)$ & $27(8.28)$ & $32(9.82)$ \\
AR & $9(2.76)$ & $55(16.87)$ & $64(19.63)$
\end{tabular}

Table.3. Distribution of patients according to the valve involvement and sex

\begin{tabular}{lccc} 
Echocardiographic finding & \multicolumn{3}{c}{ Sex distribution } \\
& Male & Female & P value \\
MS & 14 & 22 & 0.001 \\
MR & 29 & 34 & 0.1 \\
MS+ MR & 74 & 79 & 0.08 \\
AS & 4 & 1 & 0.02 \\
AR & 5 & 4 & 0.3 \\
MS+MR+AS+AR & 11 & 18 & 0.02
\end{tabular}

\section{Discussion}

Rheumatic heart disease (RHD) is the most common cardiovascular disease in children and young adults. ${ }^{1}$ Though declined and almost nonexistent in developed nations, still one of the leading cause for premature death and disability in developing countries. ${ }^{3,4}$ Many papers have been published on this topic from different countries especially from the developing nations.

In our study RHD was more common in females $54.6 \%$ than males $45.4 \%$ which is similar to Khan RF et.al, ${ }^{8}$ Shrestha $\mathrm{N}$ et $\mathrm{al}^{9}$ and Mohammed $\mathrm{F}$ et al. ${ }^{10}$ But however authors from western countries have reported it be equal in both sexes. ${ }^{11}$ Mitral valve was the most often involved valve with mixed MS and MR being the commonest pattern, similar result found by other authors too..$^{8,9,11-13}$ In our study the most common isolated lesion was MR $19.33 \%$ followed by MS $11.66 \%$, similar to that of Shrestha $N$ et al ${ }^{9}$ however Mohammed et $\mathrm{al}^{10}$ found MS to be commonest type. In our study AS was the least common similar to other studies. ${ }^{8,9,10,11,12}$ We found AS to be more common among males however Shrestha $\mathrm{N}$ et al found $A R$ to be more common among males .

We found only $2(0.6 \%)$ patients with features if infective endocarditis, however Shrestha $\mathrm{N}$ et al found $12.4 \%$ of patients with infective endocarditis. In our study it was interesting to find that out of 326 patients $88.95 \%$ of patients were getting secondary prophylaxis of RHD rather than primary. And the new cases indicated for Inj Benzathine penicillin were majority for RHD $87.5 \%$ and not rheumatic fever $12.5 \%$.

\section{Conclusion}

RHD is a common cardiovascular problem in our country and still a lot of cases of rheumatic fever remains undiagnosed as a result of which they end up in RHD which could have been prevented. So screening program for rheumatic fever and RHD should be carried out in an extensive way. Hospital based diagnosis and treatment is not sufficient, otherwise we may have to face the burden of RHD in future even more than what we have now. Health policy makers and we physicians should be aware of this 


\section{References}

1. Rhematic fever and Rheumatic Heart disease. World health organ Tech Rep Series 2004; 923:1-22.

2. Carapetis R, Steer C, Mullholland K, et al. The Global Burden of group A streptococcal diseases. Lancet Infect Dis, 2005;5(11):685-94.

3. Rheumatic fever and rheumatic heart disease. Report of WHO study group. Technical report series No 764, Geneva WHO, 1998.

4. Hyder AA, Morrow RH. Applying burdon of disease methods in developing countries; a case study from Pakistan. Am J Public Health 2000;90:1234-40.

5. Regmi PR, Pandey MR. Rheumatic fever and RHD in school children of Kathmandu city. Indian Heart J 1997;49:518-20.

6. Otto text book of clinical echocardiograph. Fourth edition. 2009. Sauders Elsevier.

7. Hurst's The Heart. Eleventh edition. 2004. The MacGraw-Hill Companies, Inc.
8. Khanf RF ,Imtiaz $\mathrm{Y}$, Ali $\mathrm{H}$, et al. Natural history and relative distribution of different valvular heart diseases in Mayo Hospital, Lahore. Ann KE Med Coll 2002;8:90-1.

9. Shrestha N, Pilgrim T, Karki P, et al. Rheumatic Heart disease Revisited: Patterns of Valvular Involvement from a Consecutive Cohort in Eastern Nepal; VN:F [1.9.12_1141].

10. Faheem M, Hafizullah M, Gul A, et al. Pattern of valvular lesion in Rheumatic Heart Disease. JPMI 2007;21(02):99-103.

11. Dajani AS. Rheumatic fever. In Braunwald E, Ziper DP, Libby $P$,editors Heart disease, a text book of cardiovascular medicine $6^{\text {th }}$ ed. WB Saunders 2001. p. 2192.

12. Naim M. Rheumatic fever and RHD at the department of child health, school of medicine, University of North Sumatera/ Dr Prigandi Hospital Medan. Paediatrica Indonesiana 1989;29:64-71.

13. Bassili A, Zhaers R, Fattah MA. Profile of secondary prophylaxis among children with RHD in Alexandrea, Egypt. Eastern Mediterranean Health J 2000;6:437-46. 